CLINICAL STUDY

\title{
Elevated ghrelin levels in preterm born children during prepubertal ages and relationship with catch-up growth
}

\author{
Feyza Darendeliler ${ }^{1}$, Firdevs Bas ${ }^{1}$, Ruveyde Bundak ${ }^{1}$, Asuman Coban ${ }^{2}$, Rian Disci ${ }^{3}$, Ozlem Sancakli ${ }^{4}$, \\ Gulbin Gokcay ${ }^{5}$, Zeynep Ince ${ }^{2}$ and Gulay Can $^{2}$ \\ ${ }^{1}$ Pediatric Endocrinology Unit, Department of Pediatrics, ${ }^{2}$ Neonatalogy Unit, Department of Pediatrics, ${ }^{3}$ Department of Biostatistics, ${ }^{4}$ Department \\ of Pediatrics and ${ }^{5}$ Social Pediatrics Unit, Department of Pediatrics, Istanbul Faculty of Medicine, Istanbul University, 34390 Istanbul, Turkey \\ (Correspondence should be addressed to F Darendeliler who is now at İstanbul Tıp Fakültesi, Cocuk Kliniği, Capa, 34390 Istanbul, Turkey; \\ Email: feyzad@istanbul.edu.tr)
}

\begin{abstract}
Background: Ghrelin, the natural ligand of the GH secretagogue receptor, has potent orexigenic effect. Ghrelin levels are negatively associated with insulin secretion, increased in anorexia, and reduced in obesity. Increased ghrelin levels may be associated with early postnatal growth in preterm born children.

Objective: Aim of this study was to evaluate ghrelin and insulin levels at prepubertal ages in preterm born children born appropriate for gestational age (AGA) or small for gestational age (SGA) and relationships with catch-up growth (CUG) in a prospective cross-sectional study.

Methods: Eighty-four preterm born children grouped as preterm SGA $(n=28)$ and preterm AGA $(n=56)$ were evaluated at age $4.7 \pm 0.2$ and $4.7 \pm 0.1$ years with respect to their ghrelin and insulin levels. Their data were compared with that of body mass index matched term SGA $(n=35)$ and term AGA $(n=44)$ children of age $4.6 \pm 0.2$ and $3.8 \pm 0.1$ years. All children had height appropriate for their target height. CUG was defined as the difference between birth size and recent size and expressed as $\Delta$ height and $\Delta$ weight SDS.

Results: Preterm SGA and preterm AGA children had similar ghrelin levels (1717.0 \pm 166.9 and $1656.5 \pm 103.8 \mathrm{pg} / \mathrm{ml}$ ), although $\Delta$ height and $\Delta$ weight SDS in preterm SGA were significantly higher than in preterm AGA children $(P<0.001)$. Ghrelin levels in both preterm groups were higher than term SGA $(469.2 \pm 132.5 \mathrm{pg} / \mathrm{ml})$ and term AGA children $(659.6 \pm 143.3 \mathrm{pg} / \mathrm{ml} ; P<0.001$ for all). $\Delta$ Height and $\Delta$ weight SDS of the term SGA children were similar to that of preterm SGA children. Ghrelin did not have correlation with CUG but had inverse correlation with recent anthropometric indices. Insulin was significantly higher in term SGA children than other groups $(P<0.001)$.

Conclusions: Preterm children have higher ghrelin levels at prepubertal ages regardless of the magnitude of their CUG. Term SGA children, on the other hand, behave differently and have lower ghrelin levels than preterm children at prepubertal ages, which may be related to elevated insulin levels in this group.
\end{abstract}

European Journal of Endocrinology 159 555-560

\section{Introduction}

Ghrelin, a 28-amino-acid peptide, is predominantly produced in the stomach but its expression has been demonstrated in several other organs including hypothalamus and pituitary gland $(1,2)$. It has been shown to be a natural ligand of growth hormone $(\mathrm{GH})$ secretagogue receptor and plays a major role in the control of somatotrop function (2). It has also been considered as a major orexigenic factor and controls energy balance, enhancing fat mass deposition, and food intake (3).

Circulating ghrelin levels are negatively associated with body mass index (BMI); ghrelin secretion is increased in anorexia and cachexia and reduced in obesity $(2,4)$. There is a strong negative association between insulin and ghrelin levels (5). In humans, circulating ghrelin levels are increased by energy restriction and decreased by food intake (6).

It has been shown that early in the neonatal period ghrelin levels increase in preterm infants $(7,8)$. Interestingly, this increase is not inhibited by food intake (7). The absence of inhibition of ghrelin by food intake has been shown in prepubertal children as well, in contrast to adults $(9,10)$. This ghrelin refractoriness to food intake from birth to childhood may suggest that this hormone may play an anabolic drive in the growth and development. In fact, it has been shown that small for gestational age (SGA) and very low birth weight infants show higher increase in ghrelin levels at birth and after birth, which may indicate increased 
physiological need for ghrelin $(8,11,12)$. Higher postprandial ghrelin levels or lower reductions in circulating ghrelin levels following IV glucose were also found in SGA born children who showed greater catch-up growth (CUG) at 1 year of age (13). Furthermore, lower cord blood ghrelin levels have been found to be associated with slower weight gain from birth to 3 months of age (14).

There are no studies concerning ghrelin levels in preterm born children in prepubertal ages. We hypothesized that various degrees of postnatal growth in preterm infants up to prepubertal ages may be related to ghrelin levels. Thus, we studied ghrelin levels in preterm born children at prepubertal ages who have shown various degrees of postnatal growth and compared their data with that of term born children.

\section{Subjects and methods}

Of 208 children who were born with a gestational age of $\leq 37$ completed weeks (36 weeks and 6 days) and followed in the Neonatology Unit for their growth, those who were at least 2 years of age at the time of investigation $(n=140)$, to allow them to have completed their CUG, were invited to participate in a prospective, cross-sectional growth study in the pediatric endocrinology and growth unit. Twenty-nine children were not reachable at the postal address and the parents of twenty-seven children refused to participate. All together, $84(37 \mathrm{~F}, 47 \mathrm{M})$ premature born children participated in the study. The groups of children who were not reachable or refused to come were found to be similar to the study population as to gestational age, birth weight, perinatal risk factors, and hospital care.

To obtain a spectrum of CUG, the preterm children were divided into subgroups with respect to their birth weight and/or length for their gestational age. Those with a birth weight and/or length $<10$ th percentile $(15,16)$ were accepted as SGA and those with a birth weight and/or length $\geq 10$ th percentile as appropriate for gestational age (AGA). Preterm SGA group is expected to show various degrees of CUG. As the control group, $79(42 \mathrm{~F}, 37 \mathrm{M})$ children born at term $(>37$ completed gestational weeks) were studied. To compare their results with that of the preterm born children appropriately, they were also subdivided as term SGA and term AGA according to the same criteria. Thus, we had preterm SGA group $(n=28 ; 15 \mathrm{~F}, 13 \mathrm{M})$, preterm AGA group $(n=56 ; 22 \mathrm{~F}, 34 \mathrm{M})$, term SGA group $(n=35 ; 22 \mathrm{~F}, 13 \mathrm{M})$, and term AGA group $(n=44 ; 19 \mathrm{~F}$, $25 \mathrm{M}$ ). All children were prepubertal (testicular volume $<4 \mathrm{ml}$ in boys, breast stage 1 in girls, and no pubic hair in both sexes) (17) and at least 2 years of age at investigation to allow them to have completed their CUG. Mean chronological age (range) was 4.7 years (3.3-6.9) in the preterm SGA group, 4.7 years (2.97.1) in the preterm AGA group, 4.6 years (2.9-7.7) in the term SGA group, and 3.8 years $(2.8-6.7)$ in the term AGA group. Term children were recruited from the control group of an ongoing parallel study. The reason why 10th percentile was chosen as the cut-off for definition of SGA is that nearly all metabolic studies done in preterm infants have used this cut-off in their studies $(18,19)$. Birth data and anthropometric parameters of the groups at investigation are seen in Table 1. Range of gestational age in the preterm group was from 24.5 to 37 weeks.

This study was done as part of the study investigating insulin resistance and body composition in this cohort of children. Detailed methods regarding recruitment of the subjects in this study and regarding the collection of medical history and physical examination in these children have been recently given in detail in this previous report (20). BMI of the children was calculated as weight $(\mathrm{kg}) /$ height $(\mathrm{m})^{2}$. Target height was calculated as mother's height + father's height/2-6.5 for girls and +6.5 for boys. Values of height, weight, target height (21), and BMI (22), and also birth data (23) were expressed as SDS. Corrected height for target height (target height SDS minus recent height SDS) was denoted as height SDS $_{\text {corrected }}$.

CUG in height was defined as the difference $(\Delta)$ between birth length SDS and current height SDS, was denoted as $\Delta$ height SDS and CUG in weight as the difference $(\Delta)$ between birth weight SDS and current weight SDS, and was denoted as $\Delta$ weight SDS.

Table 1 Anthropometric parameters of the children at birth and at investigation (mean \pm S.E.M).

\begin{tabular}{|c|c|c|c|c|}
\hline & Preterm SGA $(n=28)$ & Term SGA $(n=35)$ & Preterm AGA $(n=56)$ & Term AGA $(n=44)$ \\
\hline \multicolumn{5}{|l|}{ At birth } \\
\hline Gestational age (week) & $32.5 \pm 0.5^{\star}$ & $39.7 \pm 0.2$ & $32.6 \pm 0.4^{*}$ & $39.4 \pm 0.2$ \\
\hline Weight SDS & $-1 . \overline{9} \pm 0.2^{\dagger}$ & $-2 . \overline{5} \pm 0.2$ & $-0 . \overline{3} \pm 0.1$ & $-0 . \overline{2} \pm 0.1$ \\
\hline Length SDS & $-1.8 \pm 0.1$ & $-2.3 \pm 0.4$ & $0.1 \pm 0.2$ & $0.02 \pm 0.1$ \\
\hline \multicolumn{5}{|l|}{ At investigation } \\
\hline Chronological age (years) & $4.7 \pm 0.2$ & $4.6 \pm 0.2$ & $4.7 \pm 0.1^{*}$ & $3.8 \pm 0.1$ \\
\hline Weight SDS & $-0 . \overline{7} \pm 0.2$ & $-0 . \overline{7} \pm 0.2$ & $-0 . \overline{6} \pm 0.1^{*}$ & $0.1 \pm 0.1$ \\
\hline Height SDS & $-0.4 \pm 0.2$ & $-0.8 \pm 0.2$ & $-0.6 \pm 0.1^{*}$ & $0.2 \pm 0.1$ \\
\hline BMI SDS & $-1.1 \pm 0.3$ & $-0.8 \pm 0.3$ & $-0.6 \pm 0.2$ & $-0.1 \pm 0.1$ \\
\hline Height SDS corrected & $-0.2 \pm 0.2$ & $-0.4 \pm 0.2$ & $-0.5 \pm 0.2$ & $-0.2 \pm 0.1$ \\
\hline
\end{tabular}

${ }^{*} P<0.001 ;{ }^{\dagger} P=0.02$. SGA, small for gestational age; AGA, appropriate for gestational age; SDS, standard deviation score; BMI, body mass index. 
After an overnight fast, serum samples were drawn for serum insulin, glucose, and ghrelin levels. Among other parameters concerning insulin resistance in this cohort of children that have been presented in the previous report (20), only the results of insulin and glucose measurements will be given in conjunction with ghrelin levels in this study. HOMA-IR was calculated as insulin $(\mu \mathrm{U} / \mathrm{ml}) \times$ glucose $(\mathrm{mmol} / \mathrm{l}) / 22.5(24)$.

Sera were stored at $-70{ }^{\circ} \mathrm{C}$ until hormonal assays were done. The samples were run in the same assays using the same kits.

This study was approved by the ethical committee. Written consent was obtained from the families and children.

\section{Methods}

Hormonal assays Glucose was measured by standard equipment and methods (Roche Diagnostics using Cobas Integra kits) by hexokinase method. Serum ghrelin was measured by LINCO Research Ghrelin (total) RIA kits (St Charles, MO, USA). Intra- and inter-assay coefficients of variance were 4.4-10.0 and $14.7-16.7 \%$ respectively. The sensitivity limit of the assay was $93 \mathrm{pg} / \mathrm{ml}$. Insulin $(\mu \mathrm{U} / \mathrm{ml})$ was measured by RIA method (DSL-1600, Webster, TX, USA), and the lowest limit of detection at the $95 \%$ confidence level was $1.3 \mu \mathrm{U} / \mathrm{ml}$. Because there were quite a number of children with insulin values below this cut-off level, standards were diluted to be able to measure values between 0.1 and $1.3 \mu \mathrm{U} / \mathrm{ml}$.

\section{Statistical analyses}

An SPSS-12 program (SPSS for Windows, version 12.0; Chicago, IL, USA) was used for statistical analyses. Comparison between the means was done by parametric tests ( $t$-test). Skewed data of ghrelin and insulin were normalized by log transformation to use parametric tests. These values are expressed as geometric mean \pm s.E.M. All other parameters were expressed as arithmetic mean \pm S.E.M. Median (range) and confidence interval (95\%) are also given in Table 2 . The relationships between variables were analyzed by simple correlation (Pearson's test), general linear models and multiple regression analysis. For univariate analysis, children were divided in subgroups according to AGA or SGA, preterm or term birth and overweight status (arbitrarily defined as being in the upper half for the BMI SDS distribution in the sample). In multiple regression analysis, ghrelin was taken as dependent variable, and birth size, $\Delta$ height SDS, $\Delta$ weight SDS, recent anthropometric indices, and insulin were taken as independent variables and tested. Those independent variables that have an effect on each other were analyzed separately in the model. Significance was granted for $P \leq 0.05$.

\section{Results}

Birth data of the children as seen in Table 1 showed the expected differences between the groups. But otherwise birth weight and length of the preterm SGA and term SGA and that of preterm AGA and term AGA children were similar, except for a higher birth weight SDS of the preterm SGA children than that of term SGA children.

As seen in Table 1, all of the anthropometric parameters of the preterm SGA and term SGA children were similar at similar ages of investigation.

Comparison of the preterm AGA and term AGA children showed that preterm AGA children were older $(P<0.001)$ and their weight SDS and height SDS were lower than that of term AGA children $(P<0.001)$ but they had similar BMI SDS and corrected height for parental height at investigation (Table 1).

Preterm SGA and preterm AGA children had no significant differences with respect to anthropometric

Table 2 Ghrelin levels and postnatal growth in preterm and term children at investigation (mean \pm S.E.M).

\begin{tabular}{lcccr}
\hline & Preterm SGA $(n=28)$ & Term SGA $(n=35)$ & Preterm AGA $(n=56)$ & Term AGA $(n=44)$ \\
\hline$\Delta$ Weight SDS & $1.2 \pm 0.2$ & $1.8 \pm 0.2$ & $-0.3 \pm 0.1^{\dagger}$ & $0.3 \pm 0.2$ \\
$\Delta$ Height SDS & $1.4 \pm 0.3$ & $1.5 \pm 0.3$ & $-0.4 \pm 0.2^{\ddagger}$ & $0.2 \pm 0.1$ \\
${\text { Ghrelin }(\mathrm{pg} / \mathrm{ml})^{\mathrm{a}}}_{\text {Insulin }(\mu \mathrm{U} / \mathrm{ml})^{\mathrm{a}}}$ & $1717.0 \pm 166.9^{*}$ & $469.2 \pm 132.5$ & $1656.5 \pm 103.8^{\star}$ & $659.6 \pm 143.3$ \\
Glucose $(\mathrm{mg} / \mathrm{dl})_{\text {HOMA-IR }^{\mathrm{a}}}$ & $0.7 \pm 0.5^{*}$ & $3.7 \pm 3.2$ & $0.6 \pm 0.2$ & $1.1 \pm 0.9$ \\
\end{tabular}

${ }^{\star} P<0.001 ;{ }^{\dagger} P=0.03 ;{ }^{\ddagger} P=0.018 ;{ }^{\S} P<0.01$. Median (range) values for ghrelin (pg/ml) are 1683.9 (545.1-4795.0) in the preterm SGA group, 351.7 (93.02803.9) in the term SGA group, 1606.3 (527.9-3735.3) in the preterm AGA group, and 723.0 (120.4-3654.2) in the term AGA group. Median (range) values for insulin $(\mu \mathrm{U} / \mathrm{ml})$ are $1.2(0.1-7.8)$ in the preterm SGA group, $3.2(0.1-92.2)$ in the term SGA group, 1.0 (0.1-7.0) in the preterm AGA group, and 1.8 (0.1-28.9) in the term AGA group. Median (range) values for HOMA-IR are 0.2 (0.01-0.97), in the preterm SGA group, 0.75 (0.02-20.9) in the term SGA group, 0.2 (0.1-1.7) in the preterm AGA group, and $0.4(0-8.2)$ in the term AGA group. $\mathrm{Cl}(95 \%)$ for ghrelin (pg/ml) are 1458.1 and 2001.5 in the preterm SGA group, 525.7 and 1116.1 in the term SGA group, 1488.8 and 1919.4 in the preterm AGA group, and 711.9 and 127.3 in the term AGA group. $\mathrm{Cl}(95 \%)$ for insulin ( $\mu \mathrm{U} / \mathrm{ml})$ are 0.9 and 2.8 in the preterm SGA group, 2.6 and 16.5 in the term SGA group, 1.2 and 2.4 in the preterm AGA group, and 1.9 and 5.7 in the term AGA group. Cl (95\%) for HOMA-IR are 0.2 and 0.6 in the preterm SGA group, 0.5 and 3.6 in the term SGA group, 0.2 and 0.5 in the preterm AGA group, and 0.4 and 1.4 in the term AGA group. SGA, small for gestational age; AGA, appropriate for gestational age; HOMA-IR, homeostasis model for insulin resistance.

${ }^{\text {a }}$ alues are log transformed. 
parameters. Term SGA children were older $(P=0.005)$ and had lower BMI $(P=0.015)$ than term AGA children.

Table 2 shows that the CUG in preterm SGA children were similar to that of term SGA children and both groups had significantly higher $\Delta$ height SDS and $\Delta$ weight SDS $(P<0.001$ for all $)$ when compared with their AGA counterparts. Preterm AGA children had $\Delta$ height SDS and $\Delta$ weight SDS slightly lower than term AGA children $(P=0.03$ and $P=0.018)$.

Ghrelin levels were significantly lower in term SGA children than in preterm SGA children $(P<0.001)$ although they had the same magnitude of CUG. Preterm AGA children had higher ghrelin levels than term AGA children $(P<0.001)$. There was no difference in ghrelin levels between preterm AGA and preterm SGA children. Ghrelin in term SGA was lower than that in term AGA children but not significantly. This difference was still insignificant when controlled for BMI in univariate analysis (d.f. $=1 ; 155 ; F=0.313 ; P=0.557$ ). Ghrelin levels are shown in Fig. 1. There was no significant gender difference in ghrelin levels.

Insulin levels, as shown in Table 2, were the highest in the term SGA group and showed a great variability in all groups. As has been shown in the previous report (20), insulin was significantly higher in term SGA children than in term AGA children $(P=0.003)$ and higher than in preterm SGA children $(P<0.001)$. Preterm SGA and preterm AGA children had similar insulin levels. HOMA-IR values showed similar differences as basal insulin values. Glucose values were in normal ranges in all groups and not significantly different from each other except for a significantly lower level in preterm AGA group than in the term AGA group $(P<0.01)$.

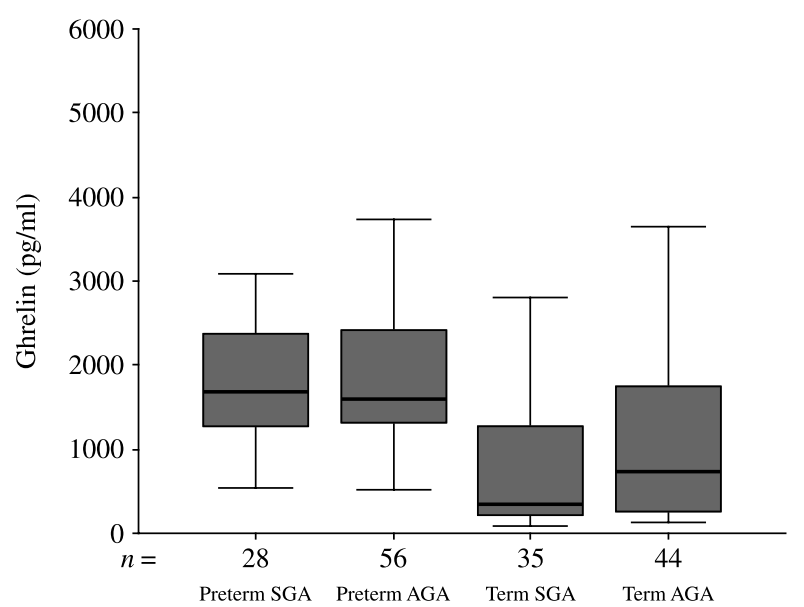

Figure 1 Ghrelin levels in preterm and term children grouped as AGA and SGA. Data are presented by box plot graphs. Boxes indicate the 25th and 75th percentiles, with a solid line with the box showing the median value and the min and max values. SGA, small for gestational age; AGA, appropriate for gestational age.

\section{Correlation studies}

There were no correlations between $\Delta$ weight SDS and $\Delta$ height SDS and ghrelin levels in any of the groups. However, ghrelin levels correlated inversely with recent height and weight in preterm $(r=-0.378, P<0.001$ and $r=-0.279, P=0.010)$ and term $(r=-0.327$, $P=0.030$ and $r=-0.361, P=0.033)$ children and additionally with BMI in term SGA children $(r=-0.389, P=0.021)$.

Ghrelin showed significant but weak negative correlation with insulin levels in preterm and term children $(r=-0.287, P=0.008$ and $r=-0.271, P=0.016)$. HOMA-IR showed significant inverse relation with ghrelin at similar levels as insulin. There was no correlation between glucose and ghrelin levels.

Multivariate analysis revealed that ghrelin level was best explained by $\left(R^{2}=0.316\right)$ insulin $(B=-0.1$, $P=0.027)$, gestational age $(B=-0.04, P<0.001)$, and recent height SDS $(B=-0.06, P=0.041)$.

\section{Discussion}

One of the findings in this study is that preterm children whether born SGA or AGA have higher ghrelin levels than term children at prepubertal ages. This finding shows that the increased levels of ghrelin in preterm born children in the early neonatal period $(7,8)$ are sustained up to prepubertal ages. This increase in ghrelin levels may be needed for the growth of these children, but it does not seem to be related to the degree of CUG because preterm SGA infants had significantly higher CUG than preterm AGA children in spite of similar ghrelin levels. Indeed, there was no correlation between $\Delta$ weight and/or $\Delta$ height and ghrelin levels. The high ghrelin levels in preterm born children in our study may be related to their low insulin levels. Most available data suggest a negative association between ghrelin and insulin levels (5) and in fact, in our study, insulin was one of the factors that explained ghrelin levels. However, high ghrelin levels may also be explained by an intrinsic characteristic of the preterm born infants. In fact, in the study by Shimizu et al. (8), it was shown that active ghrelin levels were increased in low birth weight infants in the first 8 weeks of life, and similar to our study the ghrelin levels did not differ between the AGA and SGA infants. The inverse relation of ghrelin with gestational age in our study may also imply this hypothesis. Furthermore, several studies have shown that ghrelin, besides having an effect on energy and glucose homeostasis, has an effect on gastrointestinal, cardiovascular, pulmonary and immune functions, cell proliferation and differentiation, and bone physiology (25). Thus, high ghrelin levels in preterm born children may have further implications in the development of these children. 
Although not dependent on the magnitude of CUG, ghrelin levels showed an inverse relation with the recent measured anthropometric parameters in preterm born children in our study, including weight and height in preterm and term children and BMI in term children. It has been shown that ghrelin correlates with BMI in several studies $(2,4)$ and also with weight and height in early childhood (13); however, further studies are needed to elucidate the pattern of growth and ghrelin levels in preterm born infants in early childhood.

The other important finding is that term SGA children have significantly lower ghrelin levels than preterm SGA and preterm AGA children and similar levels as term AGA children. Although the magnitude of CUG in term SGA children is the same as that of preterm SGA children, their ghrelin levels are much lower than that of preterm SGA children. This finding may be related to higher insulin levels in the term SGA children than in preterm SGA children. In fact, insulin level was one of the major determinants of ghrelin levels in our study. We, along with other investigators, have shown that SGA born children may have higher insulin levels in early childhood in spite of normal BMI levels (20, 26 28 ), and it has been shown that ghrelin has inverse correlation with insulin (5).

Although there is controversy regarding ghrelin levels at birth in preterm and term infants and relation with gestational age $(29,30)$, it has been shown that umbilical cord ghrelin concentrations are elevated in SGA neonates (12), and it was suggested that ghrelin may play a physiological role in fetal adaptation to intrauterine malnutrition. Furthermore, higher postprandial ghrelin levels or lower reductions in circulating ghrelin levels following IV glucose were associated with early postnatal growth in the first year of life of SGA infants (13). However, as can be concluded from our study, it is evident that high ghrelin levels in the early phase of growth do not seem to be sustained over the subsequent years in the growth of SGA born children. Decreased ghrelin levels in association with high insulin levels in childhood ages in term SGA children suggest that at one phase of growth in SGA children CUG occurs, high insulin levels ensue, and ghrelin levels fall. This decrease in ghrelin levels may be a compensatory mechanism to protect them from increased weight gain.

One limitation in this study may be that ghrelin levels are not analyzed with respect to food intake. It has been shown that there is a marked variation in ghrelin levels throughout the day with peaks before the food intake; however, it has also been reported that morning ghrelin levels correlate with $24 \mathrm{~h}$ ghrelin secretion (31). Thus, fasting ghrelin levels in our study should be acceptable. Another limitation in this study may be the younger age of the term AGA children. Indeed, it is not certain whether ghrelin levels are age and gender dependent (4). In the study by Soriano-Guillen et al. (32), ghrelin levels increased after birth up to 2 years of age and then decreased until the end of puberty, but in another recent study it has been shown that ghrelin levels are unchanged in childhood age to adulthood (33). Thus, the relatively narrow age range within the prepubertal period in our study is not expected to affect the ghrelin levels. There was no gender difference in our study in ghrelin levels.

Another issue of relevance may be that of ghrelin isoforms. Although the major active product of ghrelin gene is a 28 amino acid peptide acylated at the serine 3 position with an octanoyl group, recent developments have shown that ghrelin gene can generate various bioactive molecules including mainly des-acyl ghrelin and some others (25). Ghrelin isoforms are active and they may have similar or opposite physiological actions to ghrelin (2). Most published studies measure total ghrelin as we have done in our study; however, further studies regarding ghrelin isoforms in preterm born children may provide insight into the role of ghrelin in this group of children.

This is the first study that has evaluated ghrelin levels in preterm children at prepubertal ages with respect to gestation and CUG. We may conclude that the ghrelin levels are elevated in prepubertal ages in preterm children regardless of the magnitude of their CUG. Term children on the other hand behave differently than preterm children. Term SGA children have lower ghrelin levels than preterm SGA children. The lower ghrelin levels may be explained by their higher insulin levels. The finding of elevated ghrelin levels in preterm born children in prepubertal ages is a novel finding; however, further studies are needed to delineate the role of ghrelin in this group of children and on the further implications that it may have.

\section{Declaration of interest}

The authors declare that there is no conflict of interest that would prejudice the impartiality of this scientific work.

\section{Funding}

This research did not receive any specific grant from any funding agency in the public, commercial or not-for-profit sector.

\section{Acknowledgements}

We would like to express our thanks to Novo Nordisk, Turkey for financial support of the kits, our auxologist M Sukur for careful measurement of the children, N Sen in the laboratory work, and K Nokta for secretarial assistance.

\section{References}

1 Kojima M, Hosoda H, Date Y, Nakazato M, Matsuo H \& Kanqawa K. Ghrelin is a growth hormone releasing acylated peptide from stomach. Nature $1999 \mathbf{4 0 2} 656-660$.

2 Van der Lely AJ, Tschop M, Heiman ML \& Ghigo E. Biological, physiological, pathophysiological, and pharmacological aspects of ghrelin. Endocrine Reviews 200425 426-457. 
3 Casanueva FF \& Dieguez C. Ghrelin: the link connecting growth with metabolism and energy homeostasis. Reviews in Endocrine and Metabolic Disorders 20023 325-338.

4 Korbonits M, Goldstone AP, Gueorguev M \& Grossman AB. Ghrelin - a hormone with multiple functions. Frontiers in Neuroendocrinology 200425 27-68.

5 Broglio F, Gottero C, Prodam F, Destefanis S, Gauna C, Me E, Riganti F, Vivenza D, Rapa A, Martina V, Avrat E, Bona G, van der Lely AJ \& Ghigo E. Ghrelin secretion is inhibited by glucose load and insulin induced hypoglycemia but unaffected by glucagon and arginine in humans. Clinical Endocrinology $200461503-509$.

6 Ghigo E, Broglio F, Avrat E, Maccario M, Papotti M \& Muccioli G. Ghrelin: more than a natural GH secretagogue and/or an orexigenic factor. Clinical Endocrinology 200562 1-17.

7 Bellone S, Baldelli R, Radetti G, Rapa A, Vivenza D, Petri A, Savastio S, Zaffaroni M, Broglio F, Ghigo E \& Bona G. Ghrelin secretion in preterm neonates progressively increases and is refractory to the inhibitory effect of food intake. Journal of Clinical Endocrinology and Metabolism 200691 1929-1933.

8 Shimizu T, Kitamura T, Yoshikawa N, Suganuma H, Hisata K, Tanaka K, Shinohara K \& Yamashiro Y. Plasma levels of active ghrelin until 8 weeks after birth in preterm infants: relationship with anthropometric and biochemical measures. Archives of Disease in Childhood, Fetal and Neonatal Edition 200792 F291-F292.

9 Gottero C, Bellone S, Rapa A, van Koetsveld P, Vivenza D, Prodam E, Benso A, Destefanis S, Gaune C, Bellone J, Hofland L, van der Lely AJ, Bona G, Ghigo E \& Broglio F. Standard light breakfast inhibits circulating ghrelin levels to the same extent of oral glucose load in humans, despite different impact on glucose and insulin levels. Journal of Endocrinological Investigation 200326 1203-1207.

10 Bellone S, Castellino N, Broglio F, Rapa A, Vivenza D, Radetti G, Bellone J, Gottero C, Chigo E \& Bona G. Ghrelin secretion in childhood is refractory to the inhibitory effect of feeding. Journal of Clinical Endocrinology and Metabolism $2004891662-1665$.

11 Kitamura S, Yokota I, Hosoda H, Kotani Y, Matsuda J, Naito E, Ito M, Kangawa K \& Kuroda Y. Ghrelin concentration in cord and neonatal blood: relation to fetal growth and energy balance. Journal of Clinical Endocrinology and Metabolism 200388 5473-5477.

12 Farquhar J, Heiman M, Wong ACK, Wach R, Chessex P \& Chanoine JP. Elevated umbilical cord ghrelin concentrations in small for gestational age neonates. Journal of Clinical Endocrinology and Metabolism $2003 \mathbf{8 8} 4324-4327$.

13 Iniguez G, Ong K, Pena V, Avila A, Dunger D \& Merciq V. Fasting and post-glucose ghrelin levels in SGA infants: relationships with size and weight gain at one year of age. Journal of Clinical Endocrinology and Metabolism 200287 5830-5833.

14 James RJ, Drewett RF \& Cheetham TD. Low cord ghrelin levels in term infants are associated with slow weight gain over the first three months of life. Journal of Clinical Endocrinology and Metabolism 200489 3847-3850.

15 Lubchenco LO, Hansman C, Dressler M \& Boyd E. Intrauterine growth as estimated from live-born birth weight data at 24 to 42 weeks of gestation. Pediatrics 196332 793-800.

16 Lichens LO, Hangman C \& Boyd E. Intrauterine growth in length and head circumference as estimated from live births at gestational ages from 26 to 42 weeks. Pediatrics $196637403-408$.

17 Tanner JM \& Whitehouse RH. Clinical longitudinal standard for height, weight, height velocity, weight velocity and stages of puberty. Archives of Disease in Childhood 197651 170-179.

18 Hofman PL, Regan F, Jackson WE, Jefferies C, Knight DB, Robinson EM \& Cutfield WS. Premature birth and later insulin resistance. New England Journal of Medicine $20043512179-2186$.
19 Bazaes RA, Alegria A, Pittaluga E, Avila A, Iniquez G \& Mericq V. Determinants of insulin sensitivity and secretion in very-low-birthweight children. Journal of Clinical Endocrinology and Metabolism 200489 1267-1272.

20 Darendeliler F, Bas F, Bundak R, Coban A, Sancakli O, Kabatas Eryilmaz S, Kucukemre B, Disci R, Gokcay G, Aki S, Ince Z \& Eskiyurt N. Insulin resistance and body composition in preterm born children during prepubertal ages. Clinical Endocrinology $200868773-779$.

21 Neyzi O, Binyıldız P \& Alp H. Growth standards for Turkish children. Courrier 197929 553-555.

22 Cole TJ, Bellizzi MC, Flegal KM \& Dietz WH. Establishing a standard definition for child overweight and obesity worldwide: international survey. BMJ 2000320 1240-1243.

23 Niklasson A, Ericson S, Fryer JG, Karlberg J, Lawrence C \& Karlberg P. An update of the Swedish reference standards for weight, length and head circumference at birth for given gestational age (1977-1981). Acta Paediatrica Scandinavica 1991 $80756-762$.

24 Matthews DR, Hosker JP, Rudenski AS, Naylor BA, Treacher DF \& Turner RC. Homeostasis model assessment: insulin resistance and B-cell function from fasting plasma glucose and insulin concentrations in man. Diabetologia $1985 \mathbf{2 8} 412-419$.

25 Soares JB \& Leite-Moreira AF. Ghrelin, des-acyl ghrelin and obestatin: three pieces of the same puzzle. Peptides $2008 \mathbf{2 9}$ 1255-1270.

26 Mericq V, Ong KK, Bazaes R, Pena V, Avila A, Salazar T, Soto N, Iniquez $\mathrm{G} \&$ Dunger DB. Longitudinal changes in insulin sensitivity and secretion from birth to age three years in small and appropriate - for - gestational - age children. Diabetologia 200548 2609-2614.

27 Ibanez L, Ong K, Dunger DB \& de Zegher F. Early development of adiposity and insulin resistance following catch-up weight gain in small-for-gestational-age children. Journal of Clinical Endocrinology and Metabolism $2006912153-2158$.

28 Sancakli O, Darendeliler F, Bas F, Gokcay G, Disci R, Akı S \& Eskiyurt N. Insulin, adiponectin, IGFBP-1 levels and body composition in small-for-gestational age born non-obese children during prepubertal ages. Clinical Endocrinology 200869 88-92.

29 Ng PC, Lee CH, Lam CW, Chan IH, Wong E \& Fok TF. Ghrelin in preterm and term newborns: relation to anthropometry, leptin and insulin. Clinical Endocrinology 200563 217-222.

30 Bellone S, Rapa A, Vivenza D, Vercellotti A, Petri A, Radetti G, Bellone J, Broglio F, Ghigo E \& Bona G. Circulating ghrelin levels in the newborn are positively associated with gestational age. Clinical Endocrinology $200460613-617$.

31 Cummings DE, Purnell JQ, Frayo RS, Schmidova K, Wisse BE \& Weigle DS. A preprandial rise in plasma ghrelin levels suggests a role in meal initiation in humans. Diabetes 200150 1714-1719.

32 Soriano-Guillen L, Barrios V, Chowen JA, Sanchez I, Vila S, Quero J \& Argente J. Ghrelin levels from fetal life through early adulthood: relationship with endocrine and metabolic and anthropometric measures. Journal of Pediatrics 2004144 30-35.

33 Bellone S, Rapa A, Vivenza D, Castellino N, Petri A, Bellone J, Me E, Broglio F, Prodam F, Ghigo E \& Bona G. Circulating ghrelin levels as function of gender, pubertal status and adiposity in childhood. Journal of Endocrinological Investigation 200225 RC13-RC15.

Received 16 July 2008

Accepted 4 August 2008 